\title{
Neglected Spermatic Cord Twisting: Experience of the University Hospital Center of Casablanca
}

\author{
Wichou El Mehdi, Bencherki Youssef, Ettanji Adnane, Dakir Mohammed, \\ Debbagh Adil, and Aboutaieb Rachid
}

\section{ABSTRACT}

Introduction: Spermatic cord twisting (SCT) is a life-threatening emergency of the testis, causing testicular ischemic lesions by vascular constriction. Neglected SCT is an atypical variant of torsion with a late diagnostic delay. It is characterized by the presence of testicular necrosis, requiring an orchiectomy. The objective of our study is to investigate possible factors that may be responsible for the delayed diagnosis of TCS, and thus favor the occurrence of the neglected form. In order to act on these factors and prevent the harmful consequences of SCT, in particular testicular necrosis.

Material and methods: This is a retrospective and descriptive study, conducted over a period of 7 years (January 2013-December 2019). Interesting 34 patients admitted to the urology department of the CHU Ibn Rochd of Casablanca, in a neglected SCT picture. The collection of information was carried out from the patients' files through an exhaustive exploitation sheet.

Results: A total of 34 cases of neglected SCT were collected. The mean age was 17.97 years (extremes: $14-37$ years). $94 \%$ of the subjects were less than 25 years old. $15 \%$ of the subjects were from rural areas. $77 \%$ of cases occurred during the cold season. The absence of employment characterized $61.5 \%$ of the major subjects and $42.8 \%$ of the guardians of the minor patients. Only $26.5 \%$ of subjects had health coverage. Non-education characterized $62 \%$ of adult patients and $65 \%$ of guardians of minor patients. The occurrence of neglected SCT was on an ectopic testicle in 1 case $(3 \%)$ and on an oscillating testicle in 1 case $(3 \%)$. The involvement was on the left side in $70.6 \%$ of cases. The average time to visit the emergency room at the CHU was 86 hours with extremes of 12 hours and 12 days. $38 \%$ of the patients had consulted directly at the CHU, while $62 \%$ were referred from other health structures. All patients were admitted to the emergency room after the pain had disappeared (scrotal in $94 \%$ and inguinal with vacuity of the homolateral bursa in 6\%). Echodoppler allowed the dg to be applied in $100 \%$ of cases. Delayed consultation of the patient was present in $82.4 \%$ of cases. A diagnostic delay due to anaberration in medical management was found in $17.6 \%$. Therapeutic management was orchidectomy in $100 \%$ of the cases, and orchidopexy of the contralateral testis was immediate in $24 \%$ of the cases and delayed in $76 \%$ of the cases. $24 \%$ of the cases and delayed in $76 \%$ of the cases. Only $29.4 \%$ of patients presented for medical check-up at 6 months postoperatively. $80 \%$ of these patients had testicular atrophy on clinical and ultrasound examination, and frank oligospermia with asthenospermia on spermogram.

Conclusion: Multiple factors are likely to act on the prolongation of the diagnostic delay of SCT and may be at the origin of the occurrence of its neglected form. The delay in the diagnosis of SCT may be related to a delay in patient consultation or to an aberration in medical management, thus favoring the development of testicular necrosis and consequently requiring an orchiectomy. Hence the interest in knowing these factors in order to act on them by raising public awareness of the importance of emergency consultation in the face of acute scrotal pain, as well as continuing education of physicians and medical staff to prevent the occurrence of neglected SCT.

Keywords: Spermatic cord twisting, Neglected, Delay in diagnosis, Factors of delay in diagnosis, Orchidectomy.

Submitted : November 11, 2020

Published: February 22, 2021

ISSN: 2593-8339

DOI: $10.24018 /$ ejmed.2021.3.1.717

Wichou El Mehdi

Departement of Urology, Ibn Rochd University Hospital, Casablanca, Morocco.

Bencherki Youssef*

Departement of Urology, Ibn Rochd University Hospital, Casablanca, Morocco.

(e-mail:bencherki.y@ outlook.com)

Ettanji Adnane

Departement of Urology, Ibn Rochd University Hospital, Casablanca, Morocco.

Dakir Mohammed

Departement of Urology, Ibn Rochd University Hospital, Casablanca, Morocco.

Debbagh Adil

Departement of Urology, Ibn Rochd University Hospital, Casablanca, Morocco.

Aboutaieb Rachid

Departement of Urology, Ibn Rochd University Hospital, Casablanca, Morocco.

*Corresponding Author 


\section{INTRODUCTION}

Spermatic cord torsion (SCT), correspond to a rotation on the vertical axis of the testis causing the formation of spiral turns interrupting the vascularization of the testis and epididymis, resulting in ischemia damage by striction of the spermatic cord, followed by quick testicular necrosis with destruction of seminal function and, subsequently, endocrine function.

Describe for the first time by Hunter [1] in 1810, the SCT is a surgical emergency occurring mainly during the cold months of January and December, with an estimated frequency of one case in 4000 in patients under 25 years of age [2], [3]). This is an andrological emergency that can occur at any age with two peak incidences (1st year of life and puberty).

The diagnosis of SCT should be considered in first place regarding any acute scrotal pain. Its management is a race against the clock. Surgical exploration must be performed without delay, as soon as the diagnosis is made, to preserve vital and functional prognosis of the testis.

Among the atypical forms of SCT we find neglected SCT which is a variant due to late diagnosis delay. It is characterized by the presence of testicular necrosis, which requires orchiectomy as treatment. The diagnosis delay can be related to a late consultation or an aberration of medical care. In front of this situation, an orchiectomy is systematically performed.

\section{MATERIAL AND METHODS}

This is a 7 year retrospective and descriptive study, ranging from January 2013 to December 2019 at the urology department of Ibn Rochd hospital center in Casablanca. Information was collected from patients' files through an exhaustive operating sheet.

The main objective of this retrospective study is to find the factors that may be responsible for the late diagnosis of $\mathrm{SCT}$, and thus favoring the neglected form, in order to act on these elements and prevent the harmful consequences of SCT, especially testicular necrosis.

\section{RESULTS}

During the period of our study, 240 subjects were hospitalized in the urology department for SCT, of which 34 were seen late (neglected SCT), either a prevalence of $14,1 \%$ and an incidence of 5 cases per year. The mean age of our patients was 17,9 years, with extremes ranging from 14 to 37 years (Table 1 ).

TABLE 1: FREQUENCY OF NEGLECTED SCT ACCORDING TO AGE GROUPS
\begin{tabular}{ccccccc}
\hline Age & $10-14$ & $15-18$ & $19-24$ & $35-37$ & Total \\
\hline $\begin{array}{c}\text { Number of } \\
\text { patients }\end{array}$ & 2 & 21 & 9 & 2 & 34 \\
\hline
\end{tabular}

The average time of hospitalization was 86 hours with extremes ranging from 12 hours to 12 days (Table 2).
TABLE 2:DELAY OF CONSULTATION

\begin{tabular}{ccc}
\multicolumn{3}{c}{ TABLE 2:DELAY OF CONSULTATION } \\
\hline $\begin{array}{c}\text { Delay of consultation } \\
\text { on the emergency }\end{array}$ & $\begin{array}{c}\text { Number of } \\
\text { patients }\end{array}$ & Percentage \\
\hline 12-18H & 9 & $26 \%$ \\
18 h- 2 days & 7 & $21 \%$ \\
$3-5$ days & 9 & $26 \%$ \\
$6-10$ days & 7 & $21 \%$ \\
12 days & 2 & $6 \%$ \\
Total & 34 & \\
\hline
\end{tabular}

In our series, $88 \%$ of neglected SCT were spontaneous, however 2 cases $(6 \%)$, had occurred following minimal trauma and 2 other cases while riding a bike. In 24 patients $(70,6 \%)$ the SCT was on the left side, and 10 patients $(29,4 \%)$ on the right side. The onset of neglected SCT during the cold season (Winter and spring) was 26 cases (77\%).

We note that 29 patients (85\%) were from an urban area (Casablanca, Mohammedia, Khouribga, Settat) while 5 patients (15\%) lives in a rural area (Oualidia, Brouj).

In our series, $47 \%$ of subjects were out of school, while in $6 \%$, educational level was not determined. Among the educated patients, 12 minors were in secondary school (middle or high school) (35\%). 3 patients aged over 18 years old in university (9\%) and one patient aged 15 in vocational training $(3 \%)$. At this point the educational level of the people who take care of the patient seems very important to us to take it into consideration, because it had a real impact of the decision to go or not to the hospital. The distribution of the educational level of the tutor was as follows: 4 tutor with a primary school level (17\%), 1 tutor with a high school level (4\%) and 15 unschooled tutors (65\%). Regarding of the job of our adult patients, 5 were students $(38,5 \%)$ and 8 without profession $(61,5 \%)$.

Only 9 patients had health insurance, a rate of $26,5 \%$.

The great majority $(62 \%)$, initially went to another care structure, thus 11 patients consulted in a first-level hospital, 8 to a general practitioner and 2 referred by the penitentiary doctor.

Five of the patients initially seen in a first-level hospital were from a rural area and 6 from an urban one. All of the patients referred by a general practice were from the city of Casablanca, and finally Two of them were in prison. In this group, scrotal pain was present in the first consultation for 6 of our patients $(17,6 \%), 4$ had consulted a general practitioner $(11,6)$ and 2 with the penitentiary doctor $(6 \%)$. These patients had an average initial time consultation of 8 hours with extremes ranging from 5 hours to 16 hours.

The average consultation time was 95 hours (10 hours to 286 hours).

However, the Ibn Rochd university hospital center received initially only 13 patients $(38 \%)$ who all live in the city of Casablanca.

Surgical exploration was performed in all patients. All cases with an intrascrotal seat testis were approached through a transverse scrotal incision $(88 \%)$ or a longitudinal incision on the raphe of scrotum $(6 \%)$.

Surgical exploration finds a testicular necrosis that was blackish in 28 cases (82\%) (Fig. 1), and bluish in 6 cases $(18 \%)$. It also objectified a long spermatic cord in 6 patients $(17,6 \%)$. The average number of spires was 1,5 with extremes of 1 to 3 spires. 


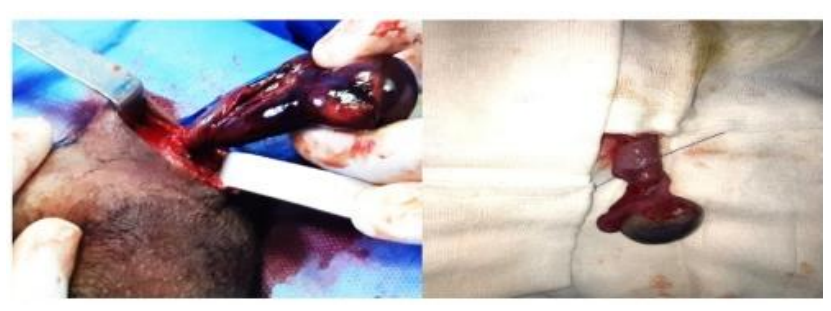

Fig. 1. Blackish necrotic testis.

The number of spires was unknown in two patients $(6 \%)$. The absence of gubernaculum testis was found in 25 patients $(73,5 \%)$ and hydrocele in 28 cases (Table 3 ).

TABLE 3:NUMBER OF PATIENT WITH HYDROCEL

\begin{tabular}{cc}
\hline Reactional hydrocel & Number of patients \\
\hline Low abundance & 24 \\
Mean abundance & 4 \\
No hydrocel & 4 \\
Total & 32 \\
\hline
\end{tabular}

For the contralateral testis, a long cord is noted in 3 cases $(8.8 \%)$, an oscillating testis in 1 case $(2.9 \%)$ and the absence of gubernaculum testis in 13 cases $(38 \%)$.

Untorsion of the spermatic cord was realized for 11 cases (no viable testis after resuscitation), and direct orchiectomy without testicular untwisting in 23 cases.

Orchidopexy of the contralateral testis was performed at the same time in 8 cases and delayed in 26 cases.

To assess the impact on the contralateral testis, a medical check-up was scheduled 6 months postoperatively. We note that only 10 patients came to the control. 8 of the patients had atrophied testis $(80 \%)$ and the rest were normal size. Ultrasound monitoring made it possible to objectify good testicular vascularization in all patients. In addition, the spermogram, oligo-astheno-spermia was found in 8 patients.

\section{DISCUSSION}

Torsion of the spermatic cord is one of the most common surgical emergencies in adolescents. Between January 2013 and December 2019, 240 cases were operated for suspected SCT in the urological department of the University Hospital of Casablanca, of which 34 actually had neglected TSC, which corresponds to a prevalence of $14 \%$ and an incidence of 5 cases per year. These 2 figures are close to the data in the literature (Table 4).

The delay in diagnosis is the main prognostic factor for the development of the SCT, given its close relationship with the duration of testicular ischemia. Thus, any diagnostic delay is likely to jeopardize the vital and functional prognosis of the organ. Our average turnaround time was 86 hours, a much shorter average than that found in the series by A. Sarr and al., which was 163 hours [4]. Theoretically, beyond six hours of evolution, irreversible histological lesions set in, leading to impairment of the endocrine and exocrine functions of the testis [4], [5].

The prognostic factors favoring testicular necrosis during SCT depend essentially on the number of turns, whether or not they are tight, and on the duration of the torsion (delay in diagnosis) [6].

The management of SCT is a race against time, it must be started as quickly as possible, in order to avoid the installation of testicular necrosis and of course the arrival at the stage of neglected SCT.

The real factors responsible for neglected spermatic cord torsion are diagnostic and therapeutic delay.

In our context, patients are responsible for the delay of management of their SCT in most cases by consulting late. This may be due to the obstacles encountered in accessing the health care services. This may be due to the obstacles encountered in accessing the health care service. Multiple constraints can delay or even hinder patient access to care.

In our series, the disadvantaged socioeconomic level was present in a good part of the cases. Thus, the absence of employment characterized $61.5 \%$ of adult subjects and $42.8 \%$ of guardians of minor patients.

The presence of health coverage facilitates access to care, so we find that people without health coverage consult less often. In our series, only 9 subjects had health coverage (26.5\%).

Some authors have established a link between access to health care services and educational level. Indeed, a low level of education can be considered as a cause of ignorance of the importance of emergency consultation before any acute scrotal symptoms. Thus, illiteracy was noted in $62 \%$ of adult patients and $65 \%$ of guardians of minor patients in our series.

In the Arab and Moroccan context, pathologies of the genitals are surrounded by great bashfulness, so patients find it very difficult to talk about their genitor sexual problems, consequently inducing a delay in consultation. In addition, the decision to consult appears to be linked to the assessment of the severity of the health problem by patients and their entourage, and is made in most cases when symptoms persist, especially for subjects residing far from health structures.

TABLE 4 : FREQUENCY OF NEGLECTED SCT ACCORDING TO OTHER SERIES

\begin{tabular}{|c|c|c|c|c|}
\hline Study & Study Period & $\begin{array}{l}\text { Number of patients with } \\
\text { spermatic torsion }\end{array}$ & $\begin{array}{l}\text { Number of patients with } \\
\text { neglected spermatic torsion }\end{array}$ & $\begin{array}{l}\text { Incidence (Number } \\
\text { of patients per year) }\end{array}$ \\
\hline A.Sarr\& al. [4] & $\begin{array}{c}\text { January } 2002-\text { December } \\
2009 \text { (9 years })\end{array}$ & 58 & $30(51 \%)$ & 4 \\
\hline O.R Bah \& al. [9] & $\begin{array}{c}\text { June } 1993 \text { - May } 2008 \text { (13 } \\
\text { years) }\end{array}$ & 27 & $5(18,5 \%)$ & 0,4 \\
\hline Hodonou R \& al. [10] & $\begin{array}{c}\text { January } 1990 \text { - December } \\
1996 \text { (7 years })\end{array}$ & 33 & $6(18 \%)$ & 1,5 \\
\hline F.A Kaboré\& al. [11] & $\begin{array}{c}\text { January - June } 2010 \text { ( } 7 \\
\text { years) }\end{array}$ & 40 & $22(55 \%)$ & 3 \\
\hline Our Study & $\begin{array}{c}\text { January } 2013-\text { December } \\
2019(7 \text { years })\end{array}$ & 240 & $34(14 \%)$ & 5 \\
\hline
\end{tabular}


In rural or peri-urban areas, various travel constraints arise such as the scarcity or even the absence of means of transport at certain times of the day or at night, the poor condition of the roads and travel costs. The in habitants can have recourse to their neighborhood or family relations, when they exist, to transport the sick to the health structures. Faced with these obstacles, this segment of society find sit self forced to post pone their consultation. In our series, $15 \%$ of the subjects were from rural areas.

In our context, the therapeutic management carried out by the attending physician in the initial admission structure (excluding $\mathrm{CHU}$ ) is also a prognostic factor impacting the evolution of SCT(delay or diagnostic error) and favoring the installation of a Neglected SCT.

Thus, we note that $17 \%$ of neglected SCT in our series, initially admitted outside the CHU in pain (scrotal and inguinal), had benefited from asymptomatic treatment (ATB and analgesic) and were only referred to the CHU a late stage where testicular necrosis was already installed. Note that the lack of specialist doctors in some hospitals in the area can also cause the delay in the management of SCT and further lengthen the duration of torsion.

Although endocrine function does not appear to be impaired by neglected SCT, there is some evidence to suggest that neglected SCT can negatively impact a man's fertility, as measured by changes in semen parameters. Indeed, the fertility of an individual can be compromised as soon as a unilateral torsion occurs, even if this is treated in time, and the spermogram is only normal in 5\% to $50 \%$ of cases during follow-up long course [7]. Several hypotheses have been put forward to explain this contralateral impairment: congenital origin; immunological origin; vascular origin [8]. According to data from the literature, patients who have atrophy or have undergone orchiectomy have significantly lower spermcounts than those without atrophy. In the study by Anderson and al. who evaluated 16 patients with TCS, including 7 patients treated by orchiectomy, they found a significant decrease in sperm density (mean sperm density 29 million/ml) [8]. Thus, the results of our series match the data in the literature. Overall, it appears that during long-term follow-up of patients after orchiectomy following neglected SCT, some show decreased spermmotility as well as a decrease in their overall number. In addition, studies are lacking to assess the clinical consequences of reduced sperm quality after SCT. For these reasons, a definitive conclusion about the longterm effects of SCT on fertility cannot be drawn. A single study looked at pregnancy rates in 63 couples where the men had been treated for SCT. They found no decrease in paternity rates in men with SCT compared to the general population: 63 files were analyzed including 41 orchidopexies and 22 orchidectomies. The pregnancy rate was $91 \%$ after removal of the gland and $90 \%$ after simple bilateral fixation with a rate of live children of $88 \%$ and $86 \%$ respectively. Pregnancy occurred in the 2 groups approximately 7 months after the surgery. Only 6 men were found to be infertile ( 2 after orchiectomy and 4 after detorsion and orchidopexy). There were 4 attempts at In Vitro Fertilization including 3 successes [8].

The pregnancy rates in this study are well within the norm for the general population of the same age group. This study makes it possible to conclude that testicular torsion, whatever its treatment, does not seem to be responsible for subsequent male infertility.

\section{CONCLUSION}

Neglected TCS represents an atypical form of TCS. It is a form of torsion seen late with a testicular necrosis, which requires orchidectomy as treatment.

The treatment is surgical in all cases, and consists of an orchidectomy of the twisted testis, with orchidopexy of the contralateral one.

Neglected TCS is mainly due to diagnosis delay. There are many factors that can influence the prolongation of the diagnosis time of TCS and can be the cause of the occurrence of this neglected form. The diagnosis delay of TCS may be linked to a delay in consulting or to an aberration in medical management.

\section{DECLARATION OF COMPETING INTEREST}

The authors state that they do not have competing interests.

\section{AVAILABILITY OF DATA AND MATERIAL}

The datasets in this article are available in the repository of the urology database, CHU Ibn-Rochd Casablanca, upon request, from the corresponding author.

\section{AUTHOR's CONTRIBUTION}

Dr. Wichou El Mehdi, Dr. Bencherki Youssef and Dr. EttanjiAdnaneanalysed and performed the literature research, Pr. Dakir Mohammed, Pr. Debbagh Adil and Pr. Aboutaieb Rachid performed the examination and performed the scientific validation of the manuscript. Wichou El Mehdi was the major contributors to the writing of the manuscript. All authors read and approved the manuscript.

\section{REFERENCES}

[1] Hunter, J. A treatise on the venereal disease. London: s.n., (1810).

[2] Anderson J, Williamson R. Testicular torsion in Bristol: a 25 year review. Bristol: Br J Surg 75:988-92, 1988.

[3] Sauvat F, Hennequin S, Ait Ali Slimane M, Gauthier F. Un age pour la torsion testiculaire? s.1. : Arch Pediatr9:1226-9, 2002.

[4] Sarr A, Fall B, Mouss B, et al. Aspects diagnostiques et thérapeutiques de la torsion du cordon spermatique au CHU AristideLe-Dantec de Dakar.Aristide-Le-Dantec de Dakar. s.l.: Andrologie 20:203-8, 2010).

[5] Lewis AG, Bukowski TP, Jarvis PD, et al. Evaluation of acute scrotum in the emergency department. s.1.: J Pediatr Surg 30:277-81, 1995.

[6] F. Audenet, M. Rouprêt. Torsion du cordon spermatique et des annexes testiculaires:s.1. : EMC - Urologie 2012;5(2):1-7 [Article 18622-A-10].

[7] Guillermet, Marc-Éric Gruénais et Élise. Décider d'accéder à des soins de santé au Maroc. Á propos du “premier délai”. s.1.: p. 71-89, 2018.

[8] www.ondh.ma. Etudes sur les disparités dans l'accès aux soins de santé au Maroc Etudes de cas. 
European Journal of Medical and Health Sciences www.ejmed.org

[9] Bah OR, Rouprêt M, Guirassy S, Diallo AB, Diallo MB, Richard F. Aspects cliniques et thérapeutiques de la torsion du cordon spermatique: étude de 27cas . s.1. : Prog Urol, 2010; 20:527-31.

[10] Hodonou R, Soumanou-Kaffo R, Akpo C. La torsion du cordon spermatique (TCS) : facteurs étiopathogéniques, diagnostiques et thérapeutiques à propos de 33 cas au CNHU de Cotonou. s.l.: Med Afr Noire 46:69-74, 1999).

[11] Traoré, F.A. Kaboré B. Zango C. Yaméogo A. Sanou B. Kirakoya S.S. Torsion of the spermatic cord in adults at Yalgado-Ouédraogo teaching hospital of Ouagadougou. s.1.: Andrologie (2011) 21:254259, 2011. 